\title{
Characterization of fluvial islands along three different gravel-bed rivers of North-Eastern Italy
}

\author{
L. Picco, ${ }^{1}$ R. Rainato, ${ }^{1}$ L. Mao L, ${ }^{2}$ F. Delai, ${ }^{1}$ A. Tonon, ${ }^{1}$ D. Ravazzolo, ${ }^{1}$ M.A. Lenzi M ${ }^{1}$ \\ ${ }^{1}$ Department of Land, Environment, Agriculture and Forestry, University of Padova, Padova, Italy \\ ${ }^{2}$ Department of Ecosystems and Environment, Pontificia Universidad Catolica de Chile, Santiago, \\ Chile
}

\begin{abstract}
River islands are defined as discrete areas of woodland vegetation located in the riverbed and surrounded by either water-filled channels or exposed gravels, exhibiting some stability and remaining exposed during bank-full flows. Islands are very important from both morphological and ecological points of view, representing the most natural condition of a fluvial system and are strongly influenced by human impacts. This study aims at analyzing the morphological and vegetation characteristics of three different typologies of islands (pioneer, young and stable) in three distinct rivers in the NE of Italy, affected by different intensities of human pressure. The study was conducted on several sub-reaches of the Piave, Brenta and Tagliamento rivers. The first is a gravel-bed river, which suffered intense and multiple human impacts, especially due to dam building and in-channel gravel mining. The same alterations can also be observed in the Brenta river, which also presents bank protections, hydropower schemes and water diversions. On the other hand, the Tagliamento river is a gravel-bed river characterized by a high level of naturality and very low human pressures. The analyses were conducted using aerial photographs and LiDAR data acquired in 2010 in order to define and distinguish the three different island typologies and to obtain a characterization of ground and vegetation features. The results suggest that the fluvial islands lie at different elevations and this fact implies a different
\end{abstract}

Correspondence: Lorenzo Picco, Department of Land, Environment, Agriculture and Forestry, University of Padova, Italy.

E-mail: lorenzo.picco@unipd.it

Key words: fluvial island, gravel bed river, piave river, tagliamento river, Brenta river.

Acknowledgements: this research was founded by both the Italian National Research Project 20104 ALME4 -ITSE: "National network for monitoring, modeling and sustainable management of erosion processes in agricultural land and hilly-mountainous area"; and The EU SedAlp Project: "Sediment management in Alpine basis: Integrating sediment continuum, risk mitigation and hydropower", 83-4-3-AT, in the framework of the European Territorial Cooperation Programme Alpine Space 2007-2013.

CC Copyright L. Picco et al., 2013

Licensee PAGEPress, Italy

Journal of Agricultural Engineering 2013; XLIV(s2):e22

doi:10.4081/jae.2013.s2.e 22

This article is distributed under the terms of the Creative Commons Attribution Noncommercial License (by-nc 3.0) which permits any noncommercial use, distribution, and reproduction in any medium, provided the orig- resistance capacity during flood events. Pioneer islands and young islands lie at lower elevations than stable islands causing a lower capacity to survive during considerable flood events, in fact in most cases those islands typologies were removed by ordinary floods. Stable islands lie at higher elevations and only intense and infrequent flood events (RI > 10-15 years) are able to determine considerable erosions. Regarding the characteristics of vegetation, we can observe a strong distinction between the three typologies. Stable islands always exhibit the greatest vegetation height and the presence of these plants, sometimes higher than $30 \mathrm{~m}$, contributes to increase the resistance and the stability of these components of fluvial systems.

\section{Introduction}

River islands are defined as discrete areas of woodland vegetation surrounded by either water -filled channels or exposed gravel (Ward $e t$ al., 1999) which exhibit some stability (Osterkamp, 1998) and remain exposed during bankfull flows. Islands have the potential of enhancing the biodiversity within the riparian zone, because their shorelines are characterized by a mosaic of habitat patches of different ages which are uncommon features along heavily managed river banks (Gurnell $e t$ al., 2001). Since islands are separated from the floodplain, they may offer a safe refuge for the wildlife from many predators. Arscott $e t$ al. (2000) found that on the Tagliamento river, the aquatic habitat complexity was greater in the island-braided section if compared to the island-devoid section. In the same river, Van der Nat et al. (2003) showed that aquatic habitats were more stable in regions of vegetated islands if compared to bar-braided regions. Stanford et al. (1996) showed that islands are most likely to be found in areas of high dynamic fluvial processes that would account for high species diversity within a wide range of riparian habitats. An early classification of straight, braided and meandering channel patterns (Leopold et al., 1964) implicitly incorporates island development through two different processes: a) the evolution of relatively stable medial bars on which vegetation can establish itself within braided channels; b) the isolation of a section of vegetated floodplain through avulsion and cut-off along meandering channels. Kellerhals et al. (1976) further discriminated between occasional, frequent, split and braided island patterns. The type of islands present in a riverine system can also help to describe the river processes. Gurnell \& Petts (2002) determined that most European rivers were once islands-dominated (pre-1900), but have become devoid of islands due to human interference. Away from areas of agricultural or urban development in Europe, islands remain a common feature of riverine landscapes, such as in the Tagliamento river (Ward et al., 1999). The presence of a certain species of plant on the island can help to determine the flow conditions in the area. Some plant species require specific growth conditions, such as inundation duration, grad ient, and particle size (Picco et al., 2012b). 
Nearly all large European rivers are flow-regulated to some degree. This can have implications for fluvial islands development and stability. Dams reduce flood peaks, increase base flow, and store sediments (Kondolf, 1997; Braatne et al., 2003). The sediment transported downstream a dam can be only a fraction of the normal sediment load. The reduced flow peaks downstream eliminate most processes of channel erosion, overbank deposition, and sediment replenishment. This also generally reduces the biologic habitat, diversity, and interactions between biotic and hydrologic processes (Poff et al., 2007). Osterkamp (1998) describes several scenarios in which islands could disappear. Perimeter sediment deposition could eliminate an island by several processes. The first is by preferential in-filling of one of the side channels that effectively raises the bed level in one anabranch but not in the other, and thereby shifts the flow into a single path. The second is by sedimentation around the whole perimeter of the island until it eventually coalesces with other nearby islands or the floodplain, again forcing the flow into a single path. A third method of island elimination occurs when the flow preferentially incises one of the side channels and leaves the other anabranch 'high and dry'. This is common downstream dams after peak flows have been reduced. If a low flow regime persists for long enough, vegetation may accumulate between an island and its floodplain. Floods can eliminate an island by two processes. The first is by simply increasing the flow to levels high enough that the entire island is eroded away. The second is by changing the main direction of the flow during a flood, thereby altering the angle of attack from the water and gradually wearing away the island by abrasion (Wyrick, 2005).

The aim of the present study is to analyze the characteristics of fluvial islands along three gravel-bed rivers affected by different levels of human pressure, as well as to better comprehend the different response to floods and to obtain more information to define more effective flood management programs, precautionary actions and to predict hydraulic hazards.

\section{Study area}

The study was conducted along three different sub-reaches of the Brenta, Piave and Tagliamento Rivers (Figure 1).

\section{Brenta river}

The Brenta River basin is located in the eastern Italian Alps (Italy) and its course interests Trentino -Alto Adige and Veneto Region (Figure 1). The study reach, called Fontaniva, features a length of around $3 \mathrm{~km}$ and it is located downstream in respect to the mountain hydrological basin $\left(1567 \mathrm{~km}^{2}\right)$ between Bassano del Grappa and Carturo Featuring an average annual precipitation of $1100 \mathrm{~mm}$ (spring and autumn are the rainiest seasons), the area presents an intermediate position between the piedmont and the floodplain. The dominant morphology of the reach is braided; the width is around $800 \mathrm{~m}$ and the average slope is 0.003 , it flows being divided in several channels which contribute to form many fluvial islands (braided pattern). The Brenta river is characterized by the presence, all over its basin, of dams, hydrological derivations and embankments. It is possible define the Brenta river as a strong affected river by human pressures.

\section{Piave river}

The Piave River rises at an elevation of 2037 m.a.s.l. and has a length of $222 \mathrm{~km}$. It flows from its source in the Dolomites to the Adriatic Sea. The drainage basin is composed mainly of sedimentary rocks (predominantly limestone and dolomite) and has an area of $4500 \mathrm{~km}^{2}$. The study reach (Figure 1) is around $3 \mathrm{~km}$ long and is located along the middle course of the Piave River, within the mountain district. The average valley gradient is about $0.004 \mathrm{~m} \mathrm{~m}^{-1}$ and the channel width ranges from $100 \mathrm{~m}$ to $1000 \mathrm{~m}$. The study reach may be described as transitional between wandering and braided morphology.

\section{Tagliamento river}

The Tagliamento River is located in the southern Alps of NorthEastern Italy. It originates at $1195 \mathrm{~m}$ a.s.l. and flows for $178 \mathrm{~km}$ to the northern Adriatic Sea, thereby forming a link corridor between the Alpine and the Mediterranean zones. Its drainage basin covers 2871 $\mathrm{km}^{2}$ (Figure 1). The hydraulic regime of the Tagliamento River is characterized by irregular discharges and high sedimentation load, due to the climatic and geological conditions of the upstream portion of the basin. The river is considered as the last morphologically intact river in the Alps, and therefore constitutes an invaluable resource. In fact the extensive vegetated islands and gravel bars are key indicators of its natural conditions, while engineering works for flood control or navigation have eliminated such features in most European water courses.

\section{Materials and Methods}

The analyses were conducted on a single dataset relating to 2010 for each river under consideration. Aerial photographs and LiDAR data were used. Aerial photographs were rectified and co-registered to a common mapping base at 1:5.000 by a GIS software (Esri ArcGIS 9.2). Approximately 30 ground-control points were used to rectify each single frame and a second order polynomial transformations were then applied. The active channel area and width were defined using the different aerial photographs and correspond to the area of water and unvegetated sediment bars.

Assuming the conceptual model of island dynamics proposed by Edwards et al. (1999), vegetated bars and pioneer islands were classified as distinct morphological units, the latter being areas with vegetation higher than $3 \mathrm{~m}$. Pioneer, young and stable islands were distinguished based on the maturity and size of the vegetation (Kollman et $a l ., 1999)$. In the aerial photos, distinction between arboreal and shrubby vegetation was made by estimating vegetation height based on canopy texture, shape and shadows. Pioneer islands were defined as surfaces on bars with patchy vegetation covered with spots of vegetation 3-5 $\mathrm{m}$ high. Young islands were distinguished because of the higher extension and dimensions, whereas stable islands were defined as older (15-20 years) areas with a high dense vegetation cover (Gurnell $\&$ Petts, 2002). Canopy height derived from the LiDAR was used to complement the aerial photographs (Zanoni et al., 2008). One airborne LiDAR flight for each river, carried out in August allowed us to analyze the vertical characteristics of the ground and vegetation of the islands. Point density of $2-3 / \mathrm{m}^{2}$ was reached after filtration. Digital Terrain Model (DTM) and Digital Surface Model (DSM) were created at $0.5 \mathrm{~m}$ resolution for each river. Based on the $0.5 \mathrm{~m}$ LiDAR resolution, the raster subtraction of the original DTM layer and the DSM layer generated the Canopy Height Model (CHM), which was used to obtain the maximum elevation of island ground and the maximum height of the island vegetation (Picco, 2010). analyzed reaches related to the active channel extension. It is possible to observe as the Brenta reach and the Tagliamento reach show similar differences, with much greater stable island sizes than the other two typologies, while along the Piave reach there is a less clear distinction between the sizes of the three different island typologies. It is rather interesting to see as, looking at the values reported in the graphs, there is a strong difference between the exten- 
sion of the islands related to the active channel area along the Brenta sub-reach than the other two rivers, in fact, for example, the median value for the stable islands is around 0.025 along the Brenta river and around 0.001 and 0.005 along the Piave river and Tagliamento river, respectively.

In Figure 3 are reported the characteristics of the ground elevation and the vegetation height of the Brenta river $\mathrm{s}$ ub- reach islands. We can observe a clear distinction in both the analyzed characteristics, with a significant distinction in the median values reported.

In Figure 4 are reported the characteristics of the ground elevation and the vegetation height on the Belluno reach islands. A lower difference, in respect to the Brenta river reach, between the ground elevation of the three different fluvial island typologies can be highlighted. In fact, there is only a difference between the median values of about $0.5 \mathrm{~m}$, while in the Fontaniva reach that value rises until around $1.3 \mathrm{~m}$. Looking at the vegetation height, it is possible to observe a clear distinction between the Piave and the Brenta river reaches, with a consistent decrease in the median values all over the three island typologies under consideration.

Finally, looking at the Cornino reach (Figure 5), it is possible to observe as, also in this case, there is a lower difference between the ground values in respect with those registered along the Brenta river. It is also interesting to see as, along the Taglimento river, some vegetated patches that could be classified as islands can rise into some hollows.

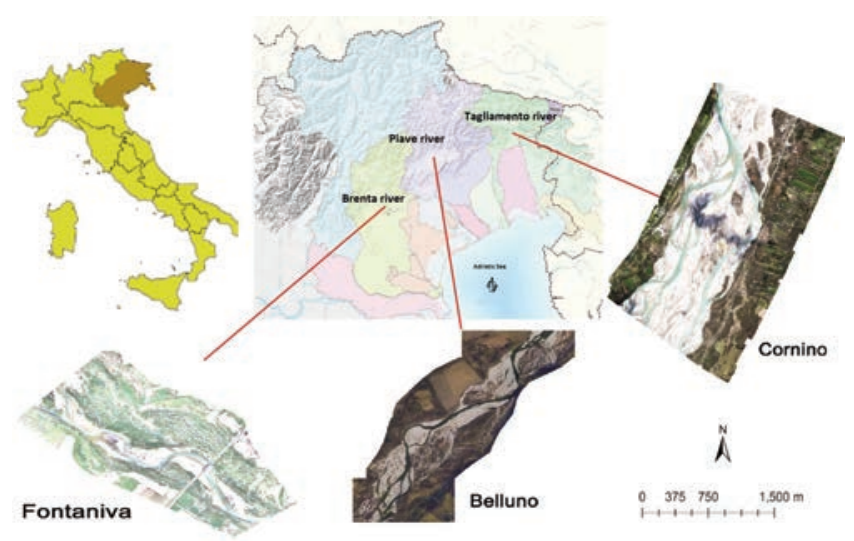

Figure 1. The study areas are located in the North-Eastern Italy, from west to east it is possible to see the Brenta river sub-reach called Fontaniva (on the bottom left), the Piave river sub-reach called Belluno (on the bottom middle) and the Tagliamento river sub-reach called Cornino (on the right). Flow direction is always from top to down.
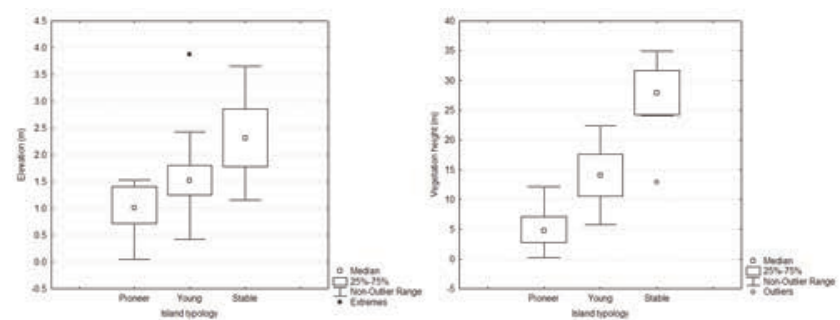

Figure 3. Maximum ground elevation of the Fontaniva sub-reach islands (on the left) and maximum vegetation height (on the right).

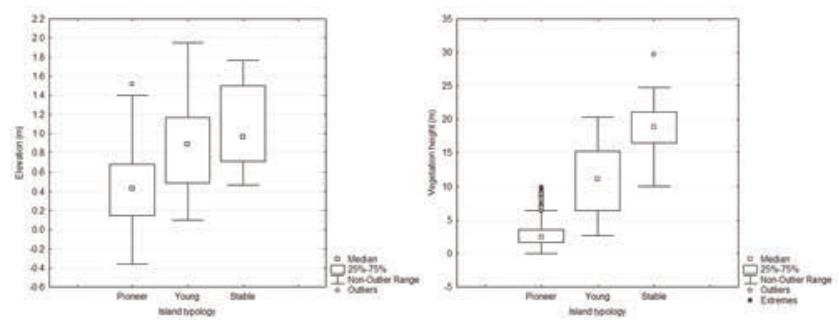

Figure 4. Maximum ground elevation of the Belluno sub-reach islands (on the left) and maximum vegetation height (on the right).

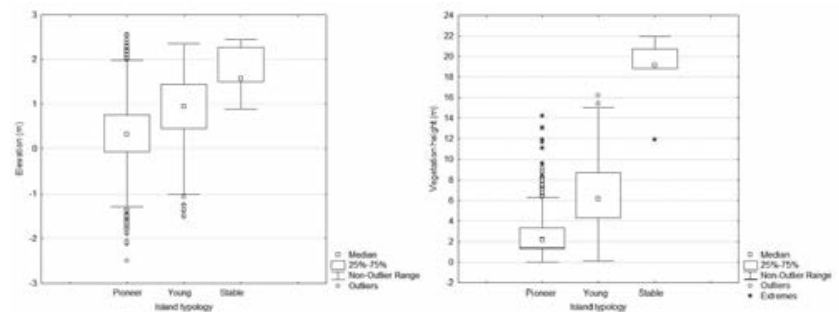

Figure 5. Maximum ground elevation of the Cornino sub-reach islands (on the left) and maximum vegetation height (on the right).
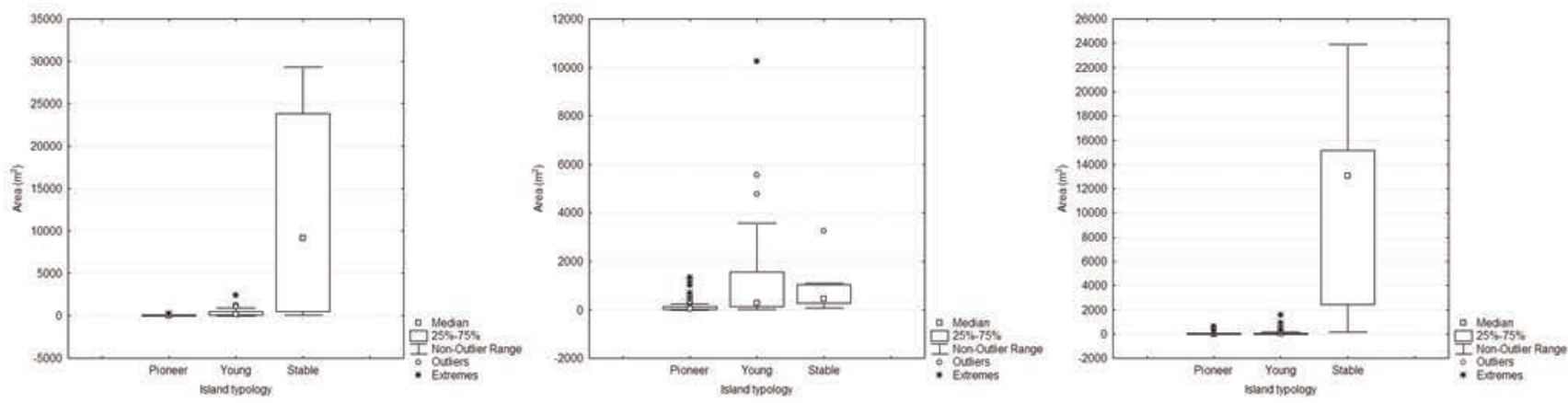

Figure 2. Variation in island size related to the active channel area along the Brenta river (on the left), the Piave river (in the middle) and the Tagliamento river (on the right). 


\section{Discussion and Conclusions}

The analysis here presented allowed us to better understand how and how much the islands can be affected by the surrounded environment. The results, in fact, show consistent differences between the three analyzed river systems. Taking into account the different human impact intensity all over the basins and along the fluvial corridor it is possible to connect the differences in size and cover, ground elevation and vegetation height of the fluvial islands with the human activities overall. In fact, the systems under consideration are theoretically comparable by the morphological, biogeographical and hydrological point of view, but these systems are affected in very different manners by human activities.

Looking at the higher cover of fluvial islands along the Brenta reach, this phenomenon is probably due to the high level of embankments that do not permit a constant sediment recruitment from the banks with consequent channel narrowing processes that allow an easier vegetation stabilization over the higher bars that are not disturbed periodically by the floods. On the other hand, along the Tagliamento river there is a higher difference between the sizes of the stable islands and the other two typologies, this is probably due to the fact thatonly the more stable islands are able to resist to the very common flood events that could happen different times per year moving huge volumes of sediments (Picco et al., submitted). These observations matched with those made by different authors (Bertoldi et al., 2009; Comiti et al., 2011; Picco et al., 2012a) wherein the island dynamics were found to be strictly associated to the occurrence of major floods (RI > 10-15 years), which are the only ones able to generate substantial island erosions.

Thanks to the LiDAR data was possible to analyze important morphometric characteristics of the different typologies of islands. As expected, stable islands lie at higher elevation. This is due to the fact that older vegetation growing on stable islands allows the deposition of fine sediments which, in turns, enhances the conditions for vegetation growth, providing even better circumstances for the vegetation to establish on stable islands (Picco et al., 2012a). The flood control (by dams) and the sediment recruitment control (by embankments), can be the factors by which dependsalso the lower difference in the ground elevation between the three island typologies along the Cornino reach, than the higher difference that is registered along the strongly affected Brenta river. In fact, a more active environment permits a mixed distribution of channels, bars and islands that, ultimately, maintain similar morphological characteristics all over the active channel do not allowing the narrowing processes seen along the Brenta river. This higher stability of the stable islands along the Fontaniva reach is, also, reflected by the very high vegetation that composes this island typology, in respect of the lower maximum height observed along the two more natural rivers under consideration.

This important analysis can be carried out with the simple detection starting from aerial photographs. This kind of analysis can be helpful also to predict the hydraulic hazard linked to the morphological changes and to formulate more effective flood management programs. Analyzing the island characteristics it is possible to observe how the fluvial system is stable, permitting to predict the potential increase in hydraulic hazards depending on the conditions and expansion of perifluvial vegetation and fluvial islands. Using LiDAR data it is possible to predict the LW characteristics, dimensions and volumes that could be moved downstream during floods in case of island erosion processes, permitting to localize areas of storage or areas that can be affected by the direct impact of LW (eg. bridges, check dams, bank protections); on the other hand it is possible to define the potential volume of sediment that can be released during island erosion. All this important information can be really useful to better define flood management programs and precautionary action such as, for example, the removal of the biggest trees from the islands located close to critical sections.

\section{References}

Arscott, D.B., Tockner K. and Ward J.V., 2000. Aquatic habitat diversity along the corridor of an Alpine floodplain river (Fiume Tagliamento, Italy), Archiv für Hydrobiologie, 149, 679-704.

Bertoldi W., Zanoni L., Tubino M., 2009. Planform dynamics of braided streams. Earth Surfaces Processes and Landforms 34, 547-557.

Braatne J.H., Rood S.B., Simons R.K., Gom L.A. and Canali G.E., 2003. Ecology of riparian vegetation of the Hells Canyon corridor of the Snake River: field data, analysis and modeling of plantresponses to inundation and regulated flows. Technical Report Appendix E. 3. 33. Idaho Power Company. Boise, Idaho, USA.

Comiti F., Da Canal M., Surian N., Mao L., Picco L., Lenzi M. A., 2011. Channel adjustments and vegetation cover dynamics in a large gravel bed river over the last 200 years. Geomorphology 125, 147159.

Edwards, P.J., Kollman J., Gurnell A., Petts G.E., Tockner K. and Ward J.V., 1999. A conceptual model of vegetation dynamics on gravel bars of a large alpine river. Wetlands Ecology and Management, 7,141-153.

Gurnell A.M., Petts G.E., Hannah D.M., Smith B.P.G., Edwards P.J., Kollmann J., Ward J.V. and Tockner K., 2001. Riparian vegetation and island formation along the gravel-bed Fiume Tagliamento, Italy. Earth Surf. Processes and Landforms, 26, 31-62.

Gurnell A.M. and Petts G.E., 2002. Island-dominated landscapes of large floodplain rivers, a European perspective. Freshwater Biology, 47, 581-600.

Kellershals R., Asce M., Church M. and Bray D.I., 1976. Classification and Analysis of River Processes. Journal of the Hydraulics Division, July, 1976.

Kondolf G.M., 1997. Hungry water: effects of dams and gravel mining on river channels. Environ. Mgmt, 21 4, 533-551.

Leopold L.B., Wolman M.G. and Miller J.P., 1964. Fluvial processes in Geomorphology. Freeman; San Francisco, USA.

Osterkamp W.R., 1998. Processes of fluvial island formation, with examples from Plum Creek, Colorado and Snake River, Idaho. Wetlands, 18, 530-545.

Picco L., 2010. Long period morphological dynamics in regulated braided gravel-bed rivers: comparision between Piave River (Italy) and Waitaki River (New Zealand), PhD thesis, University of Padova, $190 \mathrm{p}$.

Picco L., Mao L., Rigon E., Moretto J., Ravazzolo D., Delai F. and Lenzi M.A., 2012a. Medium term fluvial island evolution in relation with flood events in the Piave River. WIT Transactions on Engineering Sciences, Vol.73, 161 -172, ISSN: 1743-3553 (on-line). doi: 10.2495/DEB120141.

Picco L., Mao L., Rigon E., Moretto J., Ravazzolo D., Delai F. and Lenzi M.A., 2012b. Riparian forest structure, vegetation cover and floods events in the Piave River (Northeast of Italy). WIT Transactions on Engineering Sciences, Vol 73, 161-172, ISSN 1743-3533 (on-line). doi:10.2495/DEB120141.

Picco L., Mao L., Cavalli M., Buzzi E., Rainato R., Lenzi M.A., (submitted). Evaluating short-term morphological changes in a gravel-bed braided river using Terrestrial Laser Scanner. Geomorphology.

Poff, N.L., Olden J.D., Merritt D.M. and Pepin D.M., 2007. Homogenization of regional river dynamics by dams and global biodiversity implications. Proceedings of the National Academy of Sciences, 104,5732-5737. 
Stanford, J.A., Ward J.V., Liss W.J., Frissell C.A., Williams R.N., Lichatowich J.A. and Coutant C.C., 1996. A general protocol for restoration of regulated rivers, Regulated Rivers: Research \& Management, 12, 391-413.

Van der Nat, D., Tockner K., Edwards P.J., Ward J.V. and Gurnell A.M., 2003. Habitat change in braided flood plains (Tagliamento, NEItaly), Freshwater Biology, 48, 1799- 1812.

Ward J.V., Tockner K., Edwards P.J., Kollmann J., Bretschko G., Gurnell
A.M., Petts G.E. and Rossaro B., 1999. A reference river system for the alps: the Fiume Tagliamento. Regulated rivers: Research \& Management, 15, 63-75.

Wyrick J.R., 2005. On the formation of fluvial islands. PhD Thesis, Oregon State University, USA. 302 p.

Zanoni L., Gurnell A., Drake N. and Surian N., 2008. Island dynamics in a braided river from analysis of historical maps and air photographs. River Research and Applications, 24, 1141-1159. 